\title{
Grey Relation Analysis on the High-tech Industry and Economic Growth__Empirical Evidence from Yunnan Province of China
}

\author{
$\mathrm{Lin} \mathrm{Zhu}^{1} \& \mathrm{Bo} \mathrm{Xu}^{2,3}$ \\ ${ }^{1}$ Central University of Finance and Economics, China \\ ${ }^{2}$ Reaearch Center of Modern Service Industry of Zhejiang Province, Zhejiang Shuren University, China \\ ${ }^{3}$ Mathematics and Statistics Institution, Zhejiang Gongshang University, China \\ Correspondence: Bo Xu, Reaearch Center of Modern Service Industry of Zhejiang Province, Zhejiang Shuren \\ University, China. E-mail:cufe2011xu@sina.com
}

Received: January 19, 2017

doi:10.5539/ijbm.v12n4p213
Accepted: February 22, 2017

Online Published: March 26, 2017

\begin{abstract}
This paper discusses the development of high technology industry in Yunnan province of China in period of "post financial crisis" from the perspective of overall situation and industry sectors. Based on the data from 2008 to 2014 and by using the grey correlation model, the empirical analysis has been done about the relationship between the high technology industry and economic growth in Yunnan province. Results show that although the overall level of high technology industry development in Yunnan province is not high, and there is some problems such as imbalance of industrial development, low input of R\&D investment, poor innovation ability, the high technology industry leading role in the regional economic growth is revealed, and the grey correlation degree of high technology industries and regional economic growth is 0.71103 , second only to the construction industry. Finally, the article puts forward some policy suggestions for the development of high technology industry combined the actual development in Yunnan province.
\end{abstract}

Keywords: high-tech industry, economic growth, the grey relation degree, Yunnan of China

\section{Introduction and Literature Review}

Affected by the financial crisis of 2008 and the stage characteristics of China's own way of development, China's economy enters the new normal after ending the rapid growth of average annual nearly $10 \%$ in recent 30 years in2012.Under the pressure of economic downward ,it's the top priority for China that industrial structure adjustment, transformation of economic development patterns and cultivating the new motive force of development.

As a collection of the frontier, nationality, mountain and poverty, Yunnan Province is an underdeveloped one of China, so to promote the construction of a well-off society in an all-round way, the provincial government in 2008 for the first time puts forward the "Innovation of Yunnan" plan, which consists of determining the core position of innovation in development, building innovation environment, advancing the comprehensive innovation strategy and making the innovation through the development of various fields. In recent years, the high-tech industry of Yunnan have achieved rapid development, it has an important strategic significance for the transformation of economic growth pattern and speeding up the pace of "Innovative Yunnan Construction" that summarizng the present development situation of high technology industry, delving into the problems existing in the development of high technology industry, analyzing the role of high technology industry to economic growth and puting forward some suggestions on promoting sustained and healthy development of high technology industries of Yunnan province.

With the increasing of the importance of high technology industry to economic growth, the related theory researches have been also launched. Richard R. Nelson (1984) argues that high technology industry is the leading industry which promotes economic growth and strategic industry which increase the competitiveness of the national economy. Choi, b. (2003) argues that high technology industry has become the important engine of economic growth in major economies. Using DEA method and taking 50 states of USA for example, Raab (2006) focuses on the relationship between input and output of high technology industry, the results show that for most states the high technology industry has a promoting effect on economic growth. Using datas from 1994 to 2008 
in Finland and by empirical analysis, Jaakko Simonen1 et al. (2014) found that the high technology industry to play a significant role in promoting economic growth of Finland, is an important factors for Finland economy to recover from a deep recession in 1990's.

In China, scholars do some research on the important role of high technology industry to economic development. From the perspective of leading industry change, Du Shanwei (2003) considers that leading industry characterized by high technology will lead to dominate the industry change and constantly promote the industrial structure upgrade. Based on the empirical data of China from 1995 to 2010, useing vector auto regression model(VAR)model with error correction, and integrates impulse response and variance decomposition, Guan Xin et al.(2013) analyzes the long-term and short-term dynamic effect relationship between high-tech industrial development and transformation of economic development patterns, the research indicates: there is a cause a relationship between high-tech industrial development and transformation of economic development pattern; transformation of economic development pattern is proved to be conducive to high-tech industry, and the expansion of domestic demand promotes the upgrade of products and the value increment of industry, while the retransformation of China's industry is promoted. Being a leading industry, high-tech industry can promote the economic transformation in to an optimized

pattern which is characterized by domestic demand guided and consumption driven. Bsed on the concept of the core competitiveness and diamond model theory, using the analytic hierarchy process ,Xu Chuanshen and Zhou $\mathrm{Bo}(2014)$ discusses the impact of our country high technology industry development on China's overall competitiveness, from three aspects of the high technology industry scale, production efficiency and innovation ability. The result shows that although the competitiveness of this industry is promoted rapidly over the years, there is still a great gap compared with those of developed countries.

\section{Current Development Situation of China's Yunnan Province High-Tech Industry}

\subsection{The Overall Situation}

This paper analyzes the overall situation of high technology industry development in Yunnan, mainly from the cross industrial output value, the revenue from principal business, profits, taxex and sales revenue of new products and so on.

From the aspect of cross industrial output value, the output value of high-tech industry increased year by year in Yunnan Province, from 12.41 billion yuan in 2008 increased to 33.677 billion yuan in 2014. And calculated at current prices, high-tech industry output value in Yunnan in 2014 was 2.7 times than that in 2008. Average ratio of GDP of Yunnan is $2.4 \%$ and very smaller. From the point of growth rate, the rate of high technology industries output growth is higher than that of GDP growth in Yunnan except 2010 and 2011.At the same time, in 2012 the economy under the new normal, both present decreasing trend. Revenue from principal business increased from 11.14 billion yuan in 2008 to 31.21 billion in 2014. And calculated at current prices, revenue from principal business of high-tech industry in Yunnan in 2014 was 2.8 times than that in 2008. In addition, the average ratio of industrial enterprises above state designated scale is $2.64 \%$, slightly higher than the value of GDP.

Table 1. Production and Management of High-tech Industry of Yunnan

\begin{tabular}{|c|c|c|c|c|c|c|}
\hline Year & $\begin{array}{l}\text { Cross Industrial } \\
\text { Ourput Value } \\
\text { Current Prices } \\
\text { (100 million yuan) }\end{array}$ & $\begin{array}{l}\text { Ratio of CIOV } \\
\text { to GDP of } \\
\text { Yunnan (\%) }\end{array}$ & $\begin{array}{l}\text { Growth Rate of } \\
\text { Revenue from } \\
\text { Principal Business } \\
(\%)\end{array}$ & $\begin{array}{l}\text { Growth Rate of } \\
\text { GDP of Yunnan } \\
(\%)\end{array}$ & $\begin{array}{l}\text { Revenue from } \\
\text { Principal } \\
\text { Business } \\
(100 \quad \text { million } \\
\text { yuan) }\end{array}$ & $\begin{array}{l}\text { Ratio of Industrial } \\
\text { Enterprises above State } \\
\text { Designated Scale }(\%)\end{array}$ \\
\hline 2008 & 124.10 & 2.18 & 16.46 & 12.63 & 111.4 & 2.25 \\
\hline 2009 & 147.20 & 2.39 & 19.46 & 9.16 & 131.3 & 2.64 \\
\hline 2010 & 169.40 & 2.34 & 11.41 & 13.36 & 160.1 & 2.52 \\
\hline 2011 & 201.40 & 2.26 & 12.80 & 16.81 & 188.7 & 2.48 \\
\hline 2012 & 251.56 & 2.44 & 21.74 & 12.99 & 239.4 & 2.68 \\
\hline 2013 & 302.38 & 2.56 & 17.15 & 11.86 & 291.1 & 2.90 \\
\hline 2014 & 336.77 & 2.63 & 9.19 & 6.18 & 312.1 & 3.01 \\
\hline
\end{tabular}

Source: China Statistics Yearbook on High Technology Industry (2009-2015)

Note: Ratio calculate by author according to current prices.. 
In table 2, from the absolut number of profit and tax, both presents the increasing trend year by year before 2013 and decreasing in 2014. Sales revenue of new products generally present the rise, but fluctuant in 2010 and 2012.From perspective of the ratio,the smallest is $3.59 \%$ of 2010 and the biggest is $6.69 \%$ of 2013 for profits, the smallest is $2.38 \%$ of 2008 and the biggest is $3.31 \%$ of 2013 for taxes, the smallest is $5.67 \%$ of 2008 and the biggest is $11.82 \%$ of 2013 for sales revenue of new products.

Table 2. Ourput Benefit of High-tech Industry of Yunnan

\begin{tabular}{|c|c|c|c|c|c|c|}
\hline year & $\begin{array}{l}\text { Profits } \\
(100 \\
\text { million } \\
\text { yuan })\end{array}$ & \begin{tabular}{lrr} 
Ratio of & \multicolumn{2}{c}{ Industrial } \\
Enterprises & above & State \\
Designated & & Scale \\
Profits(\%) & &
\end{tabular} & $\begin{array}{l}\text { Taxes } \\
(100 \\
\text { million } \\
\text { yuan })\end{array}$ & \begin{tabular}{lrr} 
Ratio of & \multicolumn{2}{c}{ Industrial } \\
Enterprises & above & State \\
Designated & & Scale \\
Taxes(\%) & &
\end{tabular} & $\begin{array}{l}\text { Sales } \\
\text { Revenue of } \\
\text { NewProducts } \\
(100 \text { million } \\
\text { yuan })\end{array}$ & $\begin{array}{l}\text { Ratio of Industrial } \\
\text { Enterprises above State } \\
\text { Designated Scale SRNP } \\
(\%)\end{array}$ \\
\hline 2008 & 14.8 & 4.77 & 23.9 & 2.38 & 17.54 & 5.67 \\
\hline 2009 & 19.5 & 5.41 & 30.2 & 2.76 & 28.51 & 10.41 \\
\hline 2010 & 21.5 & 3.59 & 33.2 & 2.30 & 26.10 & 11.21 \\
\hline 2011 & 28.9 & 4.52 & 41.0 & 2.46 & 39.9 & 10.48 \\
\hline 2012 & 28.6 & 4.88 & 45.7 & 2.60 & 36.99 & 8.28 \\
\hline 2013 & 42.2 & 6.69 & 62.7 & 3.31 & 52.42 & 11.82 \\
\hline 2014 & 34.0 & 6.59 & 53.4 & 2.93 & 55.95 & 10.80 \\
\hline
\end{tabular}

Note: Ratio calculate by author according to current prices.

\subsection{Industrial Sector Situation of High-Tech Industries}

According to China's industrial R\&D input intensity, at the same time, in order to consistent with the OECD countries in statistics, National development and reform commission, National bureau of statistics and Ministry of science and technology of PRC eventually determine the scope of high-tech industry in our country, including manufacture of medicines, manufacture of aircrafts and space crafts, manufacture of electronic equipment and communication Equipment, manufacture of computer and office equipment, manufacture of medical equipment and measuring instrument.

From table 3, we know that for manufacture of medicines, exports accounted $57.22 \%$, that is the smallest than profits, taxes, cross industrial output and revenue from principal business. For manufacture of aircrafts and space crafts, exports accounted $9.42 \%$. that is the biggest than profits, taxes, cross industrial output and revenue from principal business, manufacture of medical equipment and measuring instrument is also the same.

Table 3. The average proportion of 2008-2014 high-tech industries by industrial sector of Yunnan

\begin{tabular}{|c|c|c|c|c|c|}
\hline Industrial Sector & $\begin{array}{l}\text { Cross Industrial Output } \\
\text { Value }\end{array}$ & $\begin{array}{l}\text { Revenue from Principal } \\
\text { Business }\end{array}$ & Profits & Taxes & Exports \\
\hline Manufacture of Medicines & 81.98 & 80.63 & 87.22 & 89.03 & 57.22 \\
\hline Manufacture of Aircrafts and Spacecrafts & - & - & - & - & - \\
\hline $\begin{array}{l}\text { Manufacture of Electronic Equipment and } \\
\text { Communication Equipment }\end{array}$ & 4.02 & 5.47 & 6.44 & 5.01 & 9.42 \\
\hline Manufacture of Computer and Office Equipments & 5.96 & 6.56 & 2.55 & 2.64 & 7.86 \\
\hline $\begin{array}{l}\text { Manufacture of Mecical Equipment and Measuring } \\
\text { Instrument }\end{array}$ & 8.04 & 7.31 & 3.73 & 3.20 & 25.23 \\
\hline
\end{tabular}

Note: Ratio calculate by author according to the datas from China Statistics Yearbook on High Technology Industry (2009-2015).

\subsection{The Existing Problems in the Development of High Technology Industry in Yunnan}

\subsubsection{Small Scale as a Whole}

From the perspective of proportion of high-tech industrial output value to GDP, Yunnan province in 2014 is $2.63 \%$, however Guangdong province is more than $50 \%$, which development level of high-tech industry is the best in China, even Guizhou which is the neighbour province is 7.13\%.In 2014, in terms of cross industrial output value, Yunnan province is $1.12 \%$ of Guangdong, $51.1 \%$ of Guizhou. In terms of revenue from principal 
business, in 2014 Yunnan province is $1.03 \%$ of Guangdong, 55.1\% of Guizhou. In terms of exports, in 2014 Yunnan province is $0.54 \%$ of Guangdong, $77.18 \%$ of Guizhou. Thus, for the high technology industry cross output of Yunnan province, there is not only huge gap compared with Guangdong, but also still be inferior to Guizhou .

\subsubsection{Imbalance of Industrial Sector Development}

In the five industries of high-tech industry in Yunnan, no matter in revenue from principal business and cross output value, or in taxes and profits, manufacture of medicines is more than $80 \%$,is the biggest industry of all high-tech industry sectors. And it isn't outstanding for manufacture of aircrafts and space crafts, manufacture of electronic equipment and communication equipment, manufacture of computer and office equipment, manufacture of medical equipment and measuring instrument. Therefore, the development of high technology industry in yunnan province is not balanced development.

\subsubsection{Low Input of R\&D}

The R\&D input intensity of Yunnan province in 2014 is $0.67 \%$, not only lower than $2.04 \%$ of China's level, but also lower than $2.36 \%$ of Guangdong province at the same period. In 2014, the proportion of intramural expenditure on R\&D of Yunnan accounted for National and Guangdong and Guizhou is $0.33 \%, 1.04 \%$ and $43.2 \%$ respectively. The proportion of full-time equivalent of R\&D of Yunnan accounted for National and Guangdong and Guizhou is $0.26 \%, 0.88 \%$ and $19.86 \%$ respectively. Visibly, both R\&D expenditure and personnel, Yunnan is very low.

\subsubsection{Poor Innovation Ability}

In high technology patent applications, Yunnan province is 390 pieces in 2014 , is only $0.23 \%$ of China, the share is fairly small. Compared with the Guangdong and Guizhou, accounted for $0.67 \%$ and $26.82 \%$ respectively. The number of patents in force of Yunnan is 597 in 2014, is only $0.33 \%$ of China. Compared with the Guangdong and Guizhou, accounted for $0.62 \%$ and $52.13 \%$ respectively.The sales revenue of new products for Yunnan is 5.595 billion yuan in 2014,however for Guangdong is 1058.75 billion yuan,and Guizhou is 10.618 billion yuan, the proportion accounted of Guangdong and Guizhou is $0.52 \%$ and $52.69 \%$ respectively.

\section{Methodology: Gray Relation Analysis}

Gray Relation Analysis was first proposed by Deng Julong, the professor of Huazhong University of Science and Technology (1982), and was based on the theory of gray relation space,is an important part of gray system theory. The fundamental definition of 'greyness' is information being incomplete or unknown; thus, an element from an incomplete message is considered a gray element. Gray relation means the measurement of changing relations between two systems or between two elements that occur in a system over time (Shih et al., 1994), and GRA is a research method used to measure the relationships among elements when the trends of their development have either homogeneity or heterogeneity (Deng, 1989). If two elements develop in a consistent trend, the two elements have a high level of relation. If two elements develop in an inconsistent trend, they have a low level of relation. The definition and modelling of these are as follows:

\subsection{Sequence Selecting}

There are two kinds of sequences in Gray Relation Analysis ,one is comparative sequence which is composed of factors affecting the behavior of the system, the other is referential sequence, reflect the characteristics of the system behavior. The referential sequences are $X_{0}(1), X_{0}(2), \cdots, X_{0}(n)$, the comparative sequences are $X_{1}, X_{2}, \cdots, X_{m}$. They are

$$
\begin{gathered}
X_{0}=\{X(k) \mid k=1,2, \cdots, n\} \\
X_{i}=\left\{x_{i}(1), x_{i}(2), \cdots, x_{i}(N)\right\} \quad(i=1,2, \cdots, m)
\end{gathered}
$$

\subsection{The Initial Sequence Dimensionless Processing}

Sequence datas will not compare each other because of the difference of sequence datas dimension,therefore sequence datas dimensionless processing must be done generally before calculating grey relation degree. Processing formula is: 


$$
x_{i}^{\prime}(k)=\frac{X_{i}(k)}{X_{i}(1)}, k=1,2, \cdots, n, i=0,1,2, \cdots, m
$$

\subsection{Calculating Difference}

Calculate the difference value of each sequence.Note that:

$$
\Delta_{i}(t)=\left|x_{0}^{\prime}(k)-x_{i}^{\prime}(k)\right|, k=1,2, \cdots, n, i=1,2, \cdots m
$$

Let $M=\max _{i} \max _{k}\left|x_{0}^{\prime}(k)-x_{i}^{\prime}(k)\right|, m=\min _{i} \min _{k}\left|x_{0}{ }^{\prime}(k)-x_{i}^{\prime}(k)\right|$

$\mathrm{M}$ and $\mathrm{m}$ is the maximum and minimum difference values among those different values respectively.

\subsection{Calculating the relevant coefficient}

Then the gray relevant coefficient is defined in traditional gray relation analysis as follow:

$$
\xi_{i}(k)=\frac{m+\rho M}{\left|x_{0}(k)-x_{i}(k)\right|+\rho M}
$$

In the above equation, $\xi_{i}(k)$ is the relevant coefficient. $\rho$ is distinguish coefficient, and its value is general between 0 and 1.The smaller $\rho$ is, the greater resolution is. Here let $\rho=0.5$.

\subsection{Calculating the relevant degree}

The grey relevant index between the referential sequences and the comparative sequences is defined as follow:

$$
\varepsilon_{i}=\frac{1}{n} \sum_{k=1}^{n} \xi_{i}(k), k=1,2, \cdots, n, i=1,2, \cdots m
$$

\subsection{Ranking of the Relevant Degree}

If $\varepsilon_{1}>\varepsilon_{2}$, compared with the sequence $x_{2}$, the comparative sequence $x_{1}$ is more similar to referential sequences. So finanlly,the relevant degree is ranked according to the correlation value.Generally,when the $\mathcal{E}$ $<0.3$,the relationship between the referential sequences and the comparative sequences is weak, when the $\varepsilon \in(0.3,0.5)$,the gray relationship is low,and when the $\mathcal{E} \in(0.5,0.8)$,the gray relationship is closer, when the $\varepsilon \in(0.8,1)$,the gray relationship is very closest.

\section{The empirical Analysis of Yunnan Province of China}

\subsection{Sequence Selecting}

In order to compare with other industres, according to the National Economy Industry Classification, high-tech industry will be taked as an independent industry of the National Economy, so the industry classification is as follows:

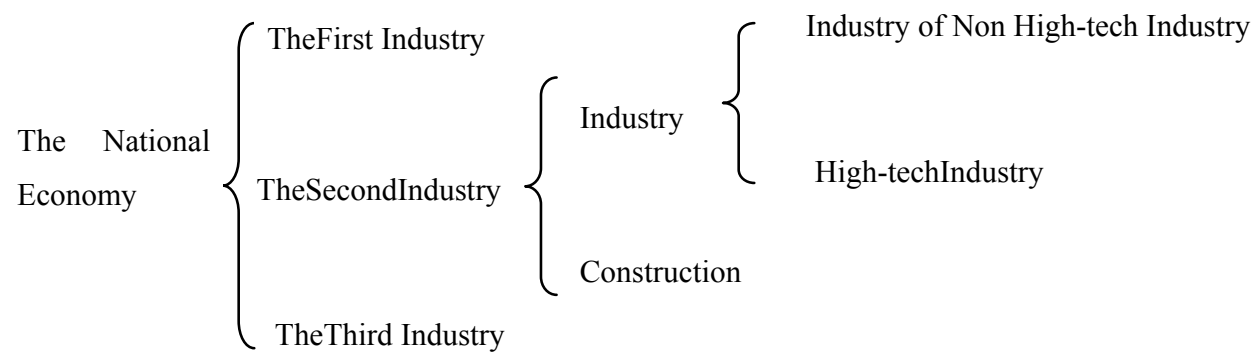

Figure 1. Industry classification of China 
The second industry includes industrial and construction, and industrial includes mining, manufacturing and electric power, gas and water production and supply industry. In order to facilitate research, this paper combines mining, electricity, gas and water production and supply industry consolidation into the non-manufacturing industry. At the same time, the above analysis shows that at present China's high technology industries are manufacturing, in order to further highlight the contribution of high technology industry to the economic growth, this pater separates the high technology industry from the manufacturing, the rest of the manufacturing industry is a non-high technology manufacturing. According to the datas availability, this article combines the non-manufacturing industry and non-high technology manufacturing into non-high technology industry.So the comparative sequence $\left(\mathrm{X}_{1}\right)$, represents for the first industry, $\left(\mathrm{X}_{2}\right)$ represents the third industry, $\left(\mathrm{X}_{3}\right)$ represents construction, $\left(\mathrm{X}_{4}\right)$ represents the high technology industry and $\left(\mathrm{X}_{5}\right)$ represents non-high technology industry, referential sequence is the GDP of 2008-2014 $\left(\mathrm{X}_{0}\right)$. The results are shown in table 4.

Table 4. The original value of comparative sequence and referential sequence (100 million yuan)

\begin{tabular}{lllllll}
\hline year & $\mathrm{X}_{0}$ & $\mathrm{X}_{1}$ & $\mathrm{X}_{2}$ & $\mathrm{X}_{3}$ & $\mathrm{X}_{4}$ & $\mathrm{X}_{5}$ \\
\hline 2008 & 5692.12 & 1020.56 & 2218.81 & 401.02 & 124.1 & 1927.63 \\
2009 & 6169.75 & 1067.60 & 2519.62 & 494.36 & 147.2 & 1940.97 \\
2010 & 7224.18 & 1108.38 & 2892.31 & 619.42 & 169.4 & 2434.67 \\
2011 & 8893.12 & 1411.01 & 3701.79 & 786.02 & 201.4 & 2792.9 \\
2012 & 10309.47 & 1654.55 & 4235.72 & 968.48 & 251.6 & 3199.12 \\
2013 & 11832.31 & 1860.80 & 5032.3 & 1182.14 & 302.4 & 3454.67 \\
2014 & 12814.59 & 1990.07 & 5542.7 & 1389.66 & 336.8 & 3555.36 \\
\hline
\end{tabular}

\subsection{Dates Resource and Processing}

The above datas are from Yunnan Statistical Yearbook (2009-2015), China Statistics Yearbook on High Technology Industry (2009-2015) and China's High Technology Industry Development Yearbook (2012-2015). To eliminate the influence of price factors, the deflator of dates are done to the constant price level of in 2000 according to the price index of different industries.

\subsection{The empirical analysis}

Because the rate of high technology industry development of Yunnan is faster than that of GDP growth, therefore the results result may be distorted if sequences $\mathrm{X}_{1}, \mathrm{X}_{2}, \ldots, \mathrm{X}_{5}$ was treated as comparative ones directly in the empirical analysis, so the dimensionless and unification of data must be done. Firstly the base must be determined that the ratio of each industry output value divided by GDP in 2002,then the ratio of the industrial output divided by of GDP from 2002 to 2014 is divided by base, thus get a new sequence $X_{i}{ }^{\prime}(i=1,2, \cdots .5)$ which is comparative sequence. And the maximize of sequence $X_{i}^{\prime}$ in every year is the referential sequence which is the optimal state. The results are shown in table 5.

Table 5. The processed value of comparative sequence and referential sequence

\begin{tabular}{lllllll}
\hline year & $X_{0}{ }^{\prime}$ & $X_{1}{ }^{\prime}$ & $X_{2}{ }^{\prime}$ & $X_{3}{ }^{\prime}$ & $X_{4}{ }^{\prime}$ & $X_{5}{ }^{\prime}$ \\
\hline 2008 & 1.00000 & 1.00000 & 1.00000 & 1.00000 & 1.00000 & 1.00000 \\
2009 & 1.13740 & 0.96514 & 1.04767 & 1.13740 & 1.09450 & 0.92895 \\
2010 & 1.21703 & 0.85576 & 1.02712 & 1.21703 & 1.07569 & 0.99519 \\
2011 & 1.25465 & 0.88494 & 1.06786 & 1.25465 & 1.03899 & 0.92736 \\
2012 & 1.33343 & 0.89514 & 1.05403 & 1.33343 & 1.11927 & 0.91631 \\
2013 & 1.41817 & 0.87713 & 1.09107 & 1.41817 & 1.17248 & 0.86216 \\
2014 & 1.53925 & 0.86619 & 1.10962 & 1.53925 & 1.20550 & 0.81928 \\
\hline
\end{tabular}

Using grey correlation model, it can be calculated that the correlation coefficient of each industry to economic growth in Yunnan province, the results are shown in table 6 . 
Table 6. The gray correlation degree

\begin{tabular}{llllll}
\hline year & $\mathcal{E}_{1}$ & $\mathcal{E}_{2}$ & $\mathcal{E}_{3}$ & $\mathcal{E}_{4}$ & $\mathcal{E}_{5}$ \\
\hline 2008 & 1.00000 & 1.00000 & 1.00000 & 1.00000 & 1.00000 \\
2009 & 0.67635 & 0.80047 & 1.00000 & 0.89352 & 0.63329 \\
2010 & 0.49911 & 0.65464 & 1.00000 & 0.71807 & 0.61872 \\
2011 & 0.49334 & 0.65838 & 1.00000 & 0.62536 & 0.52379 \\
2012 & 0.45095 & 0.56302 & 1.00000 & 0.62699 & 0.46324 \\
2013 & 0.39953 & 0.52393 & 1.00000 & 0.59435 & 0.39300 \\
2014 & 0.34847 & 0.45590 & 1.00000 & 0.51891 & 0.33333 \\
$\boldsymbol{\xi}_{i}(k)$ & 3.86775 & 4.65634 & 7.00000 & 4.97721 & 3.96537 \\
$\mathcal{E}_{i}$ & 0.55254 & 0.66519 & 1.00000 & 0.71103 & 0.56648 \\
\hline
\end{tabular}

The table 6 shows that the digressive order of correlation degree between industries and economic growth in Yunnan is construction, high-tech industry, the third industry, non-high technology industry, the first industry, that is $\varepsilon_{3}>\varepsilon_{4}>\varepsilon_{2}>\varepsilon_{5}>\varepsilon_{1}$. The results show that the correlation degree of construction industry with economic growth in Yunnan province is the largest, indicating that at present the urbanization is in accelerated process. On the one hand, GDP can be pulled by the output of construction industry directly; the proportion of construction output value accounted GDP of Yunnan rises from 7.05\% in 2008 to $10.84 \%$ in 2014, the other hand, the construction industry can speed up the pace of industrial development by promoting the related upstream and downstream industries. The correlation degree of the first industry with economic growth in Yunnan is the least, only 0.55254 , the first industry are mainly composed of planting industry, although the averaged proportion of GDP is $16.3 \%$, but there has been an decreasing trend since 2008. The non-high technology industry in Yunnan is the resource development industry mainly, which value chain is short and innovation ability is not high, so the correlation degree of the non-high technology industry between and economic growth is not high, only 0.56648 , therefore, the contribution to economic growth is not obvious. The correlation coefficient of high-tech industry and economic growth is 0.71103 , which is the highest among the industries except construction, although the proportion of high technology industry accounted by GDP is not high, development speed is faster, the pulling effect on economic growth is appearing gradually. Lastly, the correlation degree of the tertiary industry and economic growth is 0.66519 , which is the third. Due to the rapid development of modern service industry in the tertiary industry, which indicates that after the age of the financial crisis Yunnan presented the good momentum of the transformation of economic development, industrial structure is optimizing.

\section{Conclusions and Suggestions}

\subsection{Conclusions}

Post-financial-crisis era, the high technology industry of Yunnan has received rapid development, but there are some shortcomings, such as small gross scale, a big gap compared with the developed province and neighboring province. Meanwhile, the high technology industry in Yunnan province presents imbalance phenomenon, "hing alone big" of manufacturing of medicine. In spite of that, due to the high technology industry with the features of high knowledge and technology intensive, resources and energy less consume, the pulling effect and the radiating role of high technology industry to other industries began to show itself. By using the grey system model, the empirical analysis shows that the high technology industry and economic growth in yunnan province is relatively close, the correlation degree between high-tech industry and economic growth is second only to the construction industry, and much higher than other industries.

\subsection{Suggestions}

\subsubsection{Strengthen Organizing, Coordinating and Implementation of the Policy}

In recent years, under the background of rapid development of the high technology industry at home and abroad, Yunnan gradually realizes the importance of developing high technology industry, and successively introduces many policies to promote the development of high technology industry. It's the most important task in current that implementing of relevant policies and measures, breaking of factors constrainting and restricting technology innovation, the core competitiveness and market value of high technology industry as soon as possible, strengthen the integration of administrative agencies, implementing the responsibility of departments, setting up efficient, harmonious management system. 


\subsubsection{Broaden the Financing Channels and Innovating the Financing Way}

The mode of government financial support must be innovated, Yunnan government need setting up venture capital fund to promote new industry, especially for the early innovative enterprises. Yunnan shoule actively promote the cooperation of government, banks and enterprises, encourage enterprises to take full advantage of platform such as hi-tech fair docking and industry-university-research cooperation, strengthen the exchanges and cooperation of enterprises with financial institutions, the aim is to promote all kinds of financial capital to the emerging industry cluster pilot areas, key enterprises and the provincial project. Industrial policy compliance audit procedures of high-tech enterprises listed need to furtherly simplify, eligible strategic emerging industry enterprises shoule be listed to use capital market direct financing at home and abroad.

\subsubsection{Encourage Talent Introduction and Strengthen Intellectual Support}

At present the talent is the most important resource, the government of Yunnan should pay attention to talent introduction and implementation of talent strategy of strong province. Specific measures are as follows: carrying out the implementation plan of scientific and technological personnel promotion project, establishing the planning system of science and technology talent mainly containing innovative entrepreneurial support programs, youth talent training plan, outstanding youth relay plan and so on, creating a good environment for innovation entrepreneurship, implementating of preferential policies of the transformation of scientific and technological achievements.

\subsubsection{Driving the Development of the Traditional Industry by Focusing on Industry}

In recent years, the high and new technology industry such as high-end equipment manufacturing, optoelectronic industry, new material and new energy in Yunnan obtained the strongly support from the National Ministry of Science and Technology of China, meanwhile biological medicine, electronic information, new materials, petrochemical and other high and new technology industry are determined by Yunnan government as the key industry. On the one hand, Yunnan should be fully to the key industry as the breakthrough, by taking the initiative to actively participate in the international division of labor and undertaking the domestic and international industry shift, promoting industrial structure from low-end to high-end. On the other hand, it's very necessary to play the leading role of high technology industry to the traditional industry, finally the rationalization and upgrading of industrial structure will be realized.

\subsubsection{Strengthen the Main Body Status of High Technology Enterprise Innovation}

As a kind of economic organization, the main purpose of enterprise is profit, meanwhile enterprise is the basic composition unit of the industry, the direct demanders of innovation and also a basic power of the regional economic development. Therefore, to develop the high technology enterprises not only have important role to the high technology industry, but also in regional economic development. Yunnan province should take the development of high technology enterprises as the breakthrough point, on the basis of high technology products market some measures must be taken to enhance the high technology enterprise vitality and competitiveness of the market that strengthening the main body status of enterprise in the major technical research, the introduction, absorption and innovation, establishing the technology transfer mechanism feathured by "enterprises as the core and scientific research institutes as participation", enhancing the level of infrastructure of enterprise technology innovation ability, improving and implementing the preferential policies of enterprises in technology innovation .

\section{Acknowledgement}

This paper is funded by China's National Science Foundation(CNSF Project No.71663055), the Foundation of Yunnan Province Philosophy and Social Science of China(Project No.2014QN080)and Key Project of Science Foundation of Education Department of Yunnan Province(2014ZD099)

\section{References}

Chien-Ta, H. (2006). Measuring bank operations performance: an approach based on Grey Relation Analysis. Journal of the Operational Research Society, 57(4), 337-349. https://doi.org/10.1057/palgrave.jors.2601985

Choi, B. (2003). High-tech Development in Regional Economic Growth: Policy Implications of Colm O'Gorman. Stimulating High-tech Venture Greation. $R \& D$ Management, 33(2), 177.

Deng J. (1989). Introduction to grey system theory. Journal of Grey Systems, 1(1), 1-24.

Deng, J. L. (2002). Grey Prediction and Grey Decision Making. Wuhan: Huazhong University of Science and Technology Press.

Guan, X., Qiao, X. Y., \& Meng, Q. G. (2013). Empirical Research on the Relationship between High-tech 
Industrial Development and Transformation of Economic Development Pattern. China Population, Resources and Environment, 21(2), 43-50.

Jaakko, S., Rauli, S., \& Artti, J. (2015). Specialization and diversity as drivers of economic growth: Evidence from High-Tech industries. Papers in Regional Science, 94(2), 229-247.

Jin, B. (2003). The Position and Role of High-tech in China's Industrial Development. China Industrial Economics, 19(12), 5-10.

Lin, S. (2003). China's economic structure adjustment strategy. Beijing: China Social Science Press.

Raab, R. A., \& Kotamraju, P. (2006). The efficiency of the high-tech economy: Conventional development indexes versus a performance index. Journal of Regional Science, 46(3), 545-562. https://doi.org/10.1111/j.1467-9787.2006.00452.x

Shih, K. C., Wu, G. Q., \& Huang, Y. P. (1994). The Relation of Grey Information. Chyuan-Chen Technology Co. Publishing: Taipei, Taiwan.

Xu, C. S., \& Zhou, B. (2014). Research on China's high technology industry competitiveness. Seeking Truth, 26(3), 79-83.

Zhao, Y. L., \& Wei, F. (2006). Empirical Analysis on the Impetus Function of High-tech Industry Development to the Economic Growth. The Journal of Quantitative \& Technical Economics, 22(6), 44-54.

\section{Copyrights}

Copyright for this article is retained by the author(s), with first publication rights granted to the journal.

This is an open-access article distributed under the terms and conditions of the Creative Commons Attribution license (http://creativecommons.org/licenses/by/4.0/). 